\title{
RECOMMENDATIONS FOR PERIOPERATIVE MANAGEMENT OF PATIENTS WITH CARDIAC IMPLANTABLE ELECTRONIC DEVICES
}

\author{
Nikola Pavlović1 Šime Manola $^{1}$, Hrvoje Vražić², Marinko Vučić ${ }^{3}$, Sandro Brusich ${ }^{4}$, \\ Vjekoslav Radeljić ${ }^{1}$, Ivan Zeljković ${ }^{1}$, Richard Matasić ${ }^{5}$, Ante Anićc ${ }^{6}$, Ivica Benko ${ }^{1}$, \\ Željka Gavranović ${ }^{3}$ and Milana Zlatić Glogoški ${ }^{3}$; \\ Working Group on Arrhythmias and Cardiac Pacing of the Croatian Cardiac Society
}

${ }^{1}$ Institute of Postcoronary Care and Arrhythmias, Department of Cardiovascular Diseases, Sestre milosrdnice University Hospital Centre, Zagreb, Croatia; ${ }^{2}$ Institute of Cardiology,

Department of Internal Diseases, Dubrava University Hospital, Zagreb, Croatia;

${ }^{3}$ Institute of Anesthesiology and Intensive Care, Sestre milosrdnice University Hospital Centre, Zagreb, Croatia;

${ }^{4}$ Institute of Cardiovascular Diseases, Department of Internal Medicine, Rijeka University Hospital Centre, Rijeka, Croatia; ${ }^{5}$ Department of Cardiovascular Diseases, Zagreb University Hospital Centre, Zagreb, Croatia; ${ }^{6}$ Division of Cardiology, Institute of Internal Medicine, Zadar General Hospital, Zadar, Croatia

SUMMARY - Four thousand cardiac implantable electronic devices (CIED) are implanted yearly in Croatia with constant increase. General anesthesia and surgery carry some specific risk for the patients with implanted CIEDs. Since most of the surgical procedures are performed in institutions without reprogramming devices available, or in the periods when they are unavailable, these guidelines aim to standardize the protocol for perioperative management of these patients. With this protocol, most of the procedures can be performed easily and, more importantly, safely in the majority of surgical patients.

Key words: Croatia; Anesthesia, General; Cardiac Resynchronization Therapy Devices; Guideline; Perioperative Care

\section{Introduction}

Four thousand cardiac implantable electronic devices (CIED) are implanted yearly in Croatia ${ }^{1}$. CIEDs include pacemakers, implantable cardioverter-defibrillators (ICD), cardiac resynchronization therapy devices (CRT) and implantable loop recorders (ILR). Considering aging of the population and increase of implanted CIEDs in Croatia, an increasing number of patients undergo elective or urgent surgery. In a high

Correspondence to: Nikola Pavlovic, MD, Institute of Postcoronary Care and Arrhythmias, Department of Cardiovascular Diseases, Sestre milosrdnice University Hospital Centre, Vinogradska c. 29, HR-10000 Zagreb, Croatia

E-mail: nikolap12@yahoo.com

Received April 6, 2017, accepted November 17, 2017 number of cases, surgeries are carried out in hospitals, which lack both the staff and devices for reprogramming of CIEDs, or in the periods (urgency, night duties) when reprogramming is not available. It is important to note that most procedures can be done safely for patients by using standardized protocols and algorithms, as well as easy use of magnets ${ }^{2,3}$.

The aim of this document is to standardize care for these patients and their management, and to allow for safe performance of surgical procedures in most institutions in Croatia even when reprogramming is not available or is unnecessary according to the guidelines and this review.

This document is a result of modifications to the guidelines made by the Swiss Working Group on Arrhythmias and Working Group on Cardiovascular 
Anesthesiology, and the guidelines made by the Canadian Society of Cardiology $y^{2,3}$. The document has been made in cooperation with the Working Group on Arrhythmias and Electrostimulation of the Croatian Cardiac Society and anesthesiologists from the Sestre milosrdnice University Hospital Centre.

\section{Potential Perioperative Risks}

The risks for CIEDs relate primarily to the use of electrocautery and electromagnetic interference with the device. The use of electrocautery can cause:

a) inhibition of pacing in patients who are vitally dependent on cardiac pacing*;

b) inappropriate anti-tachycardia pacing (ATP) or ICD shock delivery in patients with an ICD*;

c) inappropriate fast pacing in patients with the activated rate response function; and

d) direct mechanical damage of the device and/or electrodes*; (a) and (b) may be life-threatening.

Risks primarily depend on the following 4 factors:

1. Site of surgery

The probability of electromagnetic interference is much higher for the procedures carried out less than $15 \mathrm{~cm}$ away from the CIED. The more away the procedure is carried out, the interference is less likely. For example, procedures beneath the umbilical line have almost no risk of interference.

\section{Basic cardiac rhythm}

Only a few patients with pacemakers are completely, vitally dependent on anti-bradycardia pacing (patients with ventricular asystole). Others have some degree of their own rhythm and therefore the risks/ consequences of the possible pacing inhibition are smaller.

3. Type and way of programming CIEDs

The CIEDs with unipolar electrodes or unipolar programmed pacing have a higher possibility of interference in comparison with the bipolar ones. Inappropriately fast pacing may be caused by CIED manipulation or in CIEDs that have activity sensors. CIEDs which have minute ventilation sensors (some pacemakers and ICDs produced by Sorin and Boston Scientific) have the possibility to increase heart rate by monitoring the increase of minute volume. During mechanical ventilation, there is a risk of a significant increase of pacing frequency, which can be misinterpreted as ventricular tachycardia (VT) or even cause
VT. The magnet application excludes this option in the case of pacemakers, whereas ICDs (produced by Sorin and Boston Scientific) need to be reprogrammed.

4. Type of cautery used in surgery

Electromagnetic interference is more frequent when using unipolar electrocautery, so the use of bipolar electrocutters is preferred for these patients. When using unipolar electrocautery, the indifferent electrode should be placed as far as possible from the CIED (upper part of the leg). It is recommended to use short $(<5$ seconds) applications with 5 -second breaks between the use ${ }^{4}$.

\section{Basic Functions of Magnet Applied to CIEDs}

The CIED response to the use of magnets (and locating CIED in the magnetic field) is specific to the type of CIED and depends on the manufacturer and the model of the $\mathrm{CIED}^{5}$. Response to the magnet application is active as long as the magnet is placed above the device. It is important to note that the magnet should be available in all Emergency Departments, as well as in operating rooms/units where surgical or invasive procedures are performed. Also, all staff members in these units should know the location of the magnet and the situations in which it should be used and how to use it.

In the case of overweight patients, one should sometimes use two magnets to achieve the expected magnet response. The magnet can be fixated (glued) to the CIED subclavicular location in surgeries during which the patient is lying down in prone position. Although most requests for perioperative CIED testing are related to battery voltage, battery depletion is very rare in patients having undergone regular follow-ups, which is supported or proven by reviewing patient history. Additionally, if there is an expected response to the magnet application, it can be concluded that battery voltage is sufficient for the normal CIED function.

\section{Pacemakers}

Applying magnet over the pacemaker can be used for the purposes of diagnosis and treatment. By applying the magnet, the pacemaker (PM) is being reprogrammed automatically in asynchronous mode of pacing (AOO, VOO, DOO), which means that the PM is 'neglecting' impulses that are being sensed and paced 
Table 1. Pacemakers - responses to applying magnet

\begin{tabular}{|l|l|}
\hline Manufacturer & Response to applying magnet \\
\hline Biotronik & $\begin{array}{l}\text { Asynchronous mode (AOO, } \\
\text { VOO, DOO) for 10 contractions, } \\
\text { than return to synchronous mode }\end{array}$ \\
\hline Boston Scientific ${ }^{\#}$ & $\begin{array}{l}\text { Asynchronous mode } \\
\text { (AOO, VOO, DOO), frequency } \\
100 / \text { min* }^{*}\end{array}$ \\
\hline Medtronic & $\begin{array}{l}\text { Asynchronous mode } \\
\text { (AOO, VOO, DOO), frequency } \\
85 / \text { min* }^{*}\end{array}$ \\
\hline St. Jude Medical & $\begin{array}{l}\text { Asynchronous mode } \\
\text { (AOO, VOO, DOO), frequency } \\
100 / \text { min }^{*}\end{array}$ \\
\hline $\begin{array}{l}\text { Asynchronous mode } \\
\text { (AOO, VOO, DOO), frequency } \\
96 / \text { min }^{*}\end{array}$ \\
\hline
\end{tabular}

\#nowadays very rare in Croatia; *response can be switched off by pacemaker programming

at the default frequency (which is manufacturer-specific). There are manufacturers for which it is possible to deactivate the specific response to the use of magnet when testing/programming the PM (St. Jude Medical, Boston Scientific). The PM responses to the magnet usage are shown in Table 1.

\section{Implantable Cardioverter-Defibrillators}

The magnet usage with implantable cardioverterdefibrillators (ICD) excludes detection and therapy of ventricular arrhythmias (anti-tachycardia pacing and shocks), whereas the use of magnet does not affect anti-bradycardia pacing. However, most patients do not need anti-bradycardia pacing, although up to $25 \%$ of patients with ICD periodically need stimulation. An exception to this rule are ICDs produced by Sorin (currently very rare in Croatia), which in addition to turning off detection and ventricular arrhythmias (VT/VF), stimulate in the asynchronous mode of pacing (as in pacemakers) (Table 2).

If during the magnet usage patient develops malignant ventricular arrhythmia (VT or VF), there are two options to act: the magnet which activates ICD detection and therapy (if not previously deactivated by reprogramming) can be removed, or the magnet usage is continued with external defibrillation. All the men-
Table 2. Implantable cardioverter-defibrillators - responses to applying magnet

\begin{tabular}{|c|c|c|}
\hline Manufacturer & $\begin{array}{l}\text { Anti-bradycardia } \\
\text { function }\end{array}$ & $\begin{array}{l}\text { Anti-tachycardia } \\
\text { function }\end{array}$ \\
\hline Biotronik & None & $\begin{array}{l}\text { Detection/therapy } \\
-\mathrm{OFF}^{+}\end{array}$ \\
\hline $\begin{array}{l}\text { Boston } \\
\text { Scientific }{ }^{\#}\end{array}$ & None & $\begin{array}{l}\text { Multiple answers } \\
\text { are possible. With } \\
\text { some devices, the } \\
\text { magnet is applied } \\
\text { only once, with } \\
\text { others it must be } \\
\text { applied } \\
\text { continuously, and } \\
\text { with some the } \\
\text { response to magnet } \\
\text { can be turned off }\end{array}$ \\
\hline Medtronic & None & $\begin{array}{l}\text { Detection/therapy } \\
\text { - OFF }\end{array}$ \\
\hline $\begin{array}{l}\text { St. Jude } \\
\text { Medical }\end{array}$ & None & $\begin{array}{l}\text { Detection/therapy } \\
\text { - OFF* }\end{array}$ \\
\hline Sorin ${ }^{\#}$ & $\begin{array}{l}\text { Asynchronous } \\
\text { mode } \\
\text { (AOO, VOO, } \\
\text { DOO), } \\
\text { frequency } \\
96 / \mathrm{min}\end{array}$ & $\begin{array}{l}\text { Detection/therapy } \\
\text { - OFF }\end{array}$ \\
\hline
\end{tabular}

\#nowadays very rare in Croatia; *response can be switched-off with programming the pacemaker; ${ }^{+}$in new ICD generation during 8 hours

tioned magnet responses are expected in CIEDs with normal function and appropriate battery voltage. If there is no response to the use of magnet, there are a few options:

a) the magnet is used at a wrong site or it does not reach the device (for example, in overweight patients);

b) the battery is depleted; and

c) the magnet response is deactivated (option in ICDs produced by St. Jude Medical, Boston Scientific and some Biotronik devices).

\section{Preoperative Care}

Before surgery, it is necessary to determine that the patient has an implanted CIED, then the CIED type, its manufacturer and programming mode. 


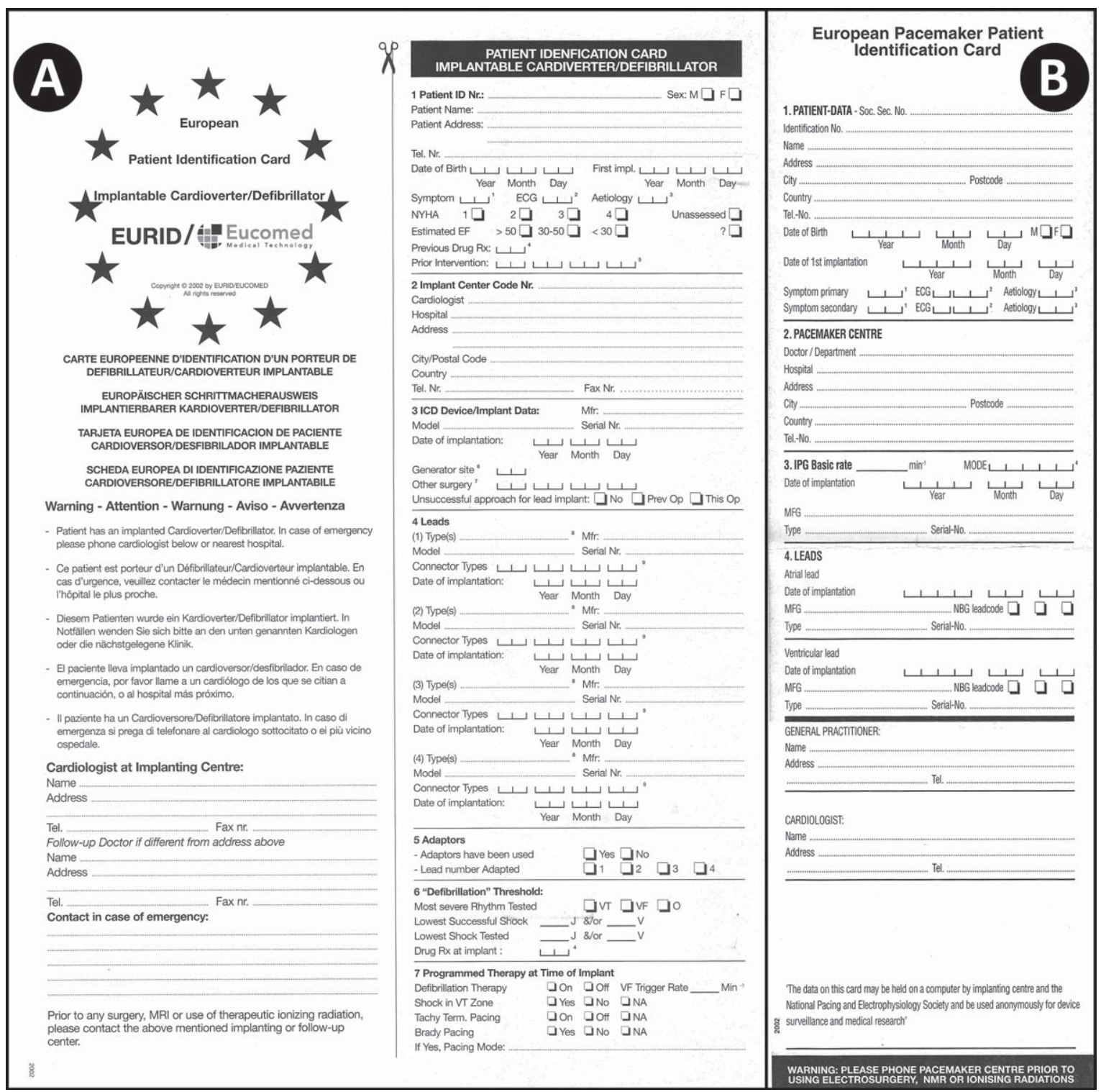

Fig. 1. Identification card of a patient with a pacemaker (left) and cardioverter defibrillator (right). Data on the manufacturer, device and programming are shown.

In the case of elective surgery, this information is available on the basis of the patient's identification card (Fig. 1), which includes all the relevant information and patients are recommended to carry it along, or on the basis of the available medical records (patients who undergo regular follow-ups in outpatient clinics).

In emergency situations, postoperative scar located in the left or right pectoral/subclavicular region indicates the presence of CIED. Rarely, it can be placed in the upper abdomen. Radiologically (chest x-ray), most important is to determine which CIED type (PM,
ICD or CRT) is implanted. It is important because the magnet response differs between PMs and ICDs.

On chest $\mathrm{x}$-ray, ICD electrodes are clearly differentiated from PM electrodes by visible 'thickness', which corresponds to the helix for high-energy delivery (defibrillation) (Fig. 2A and 2B).

Furthermore, it is possible to determine that the CIED is intended for resynchronization therapy (CRT) (Fig. 2C); there is an electrode in coronary sinus (over the left ventricle), which has to be considered in the light of heart failure indication for this 


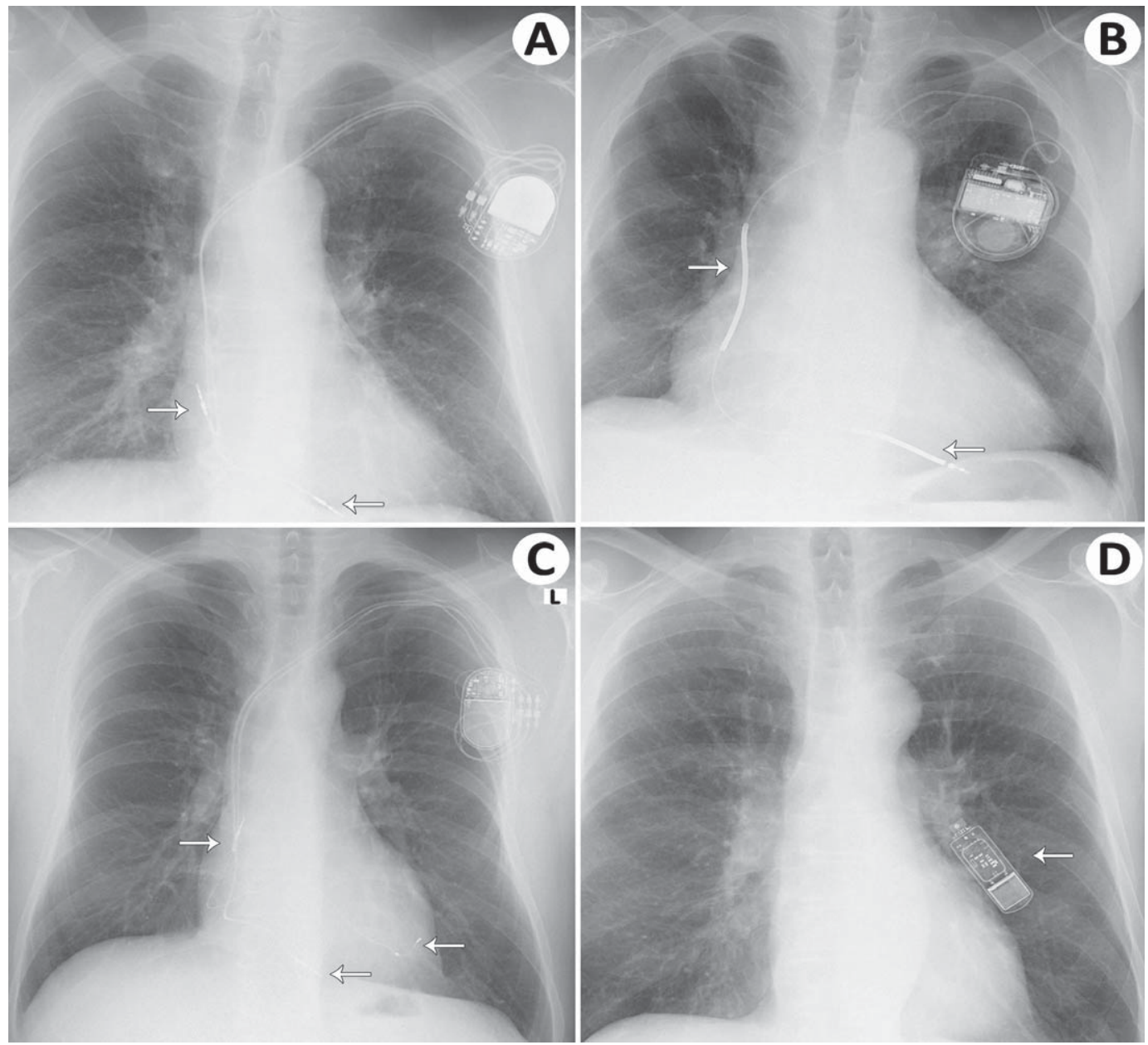

Fig. 2. Postero-anterior chest $x$-ray: (A) pacemaker can be recognized by the generator in the left pectoral region and two 'thin' electrodes in the right atrial appendage and right ventricular apex (arrows). In this case, double-chamber (DDD) pacemaker is shown (options with one lead in the ventricle or very rarely only in the atrium are possible); (B) cardioverter defibrillator can be recognized by coils on the leads, which deliver high-energy shocks (arrows). Options with one, two or three leads are possible (three leads if it is a CRT-D device); (C) cardiac resynchronization therapy (CRT-P) device. This device can be recognized by the presence of additional lead in the coronary sinus - left ventricle (arrow). Options without atrial lead or with ICD leads are possible; (D) implantable loop recorder (ILR), which is implanted left parasternally and has no leads in or outside the heart.

CIED and that these patients have a relatively high risk of developing acute heart failure and volume overload.

Patients with an implantable loop-recorder (ILR) (Fig. 2D) do not need reprogramming and do not develop perioperative risk related to the CIED except for direct mechanical damage during surgeries in the same anatomical position. In this case, it is necessary to stress to the patients to mention this at the next follow-up because some arrhythmias could be detected, which in fact could be interference rather than true arrhythmias.

The device manufacturer can also be determined by chest $\mathrm{x}$-ray with large battery enlargement (this is rarely needed).

After determining the type of the CIED, while planning further management, it should be determined whether the patient is vitally dependent on anti-bradycardia pacing. This is known on the basis of medical records or 12-lead electrocardiography 
Table 3. Indications for cardiac implantable electronic device (CIED) reprogramming

\begin{tabular}{|c|c|c|c|c|}
\hline \multirow[b]{2}{*}{ Operation } & \multirow[b]{2}{*}{$\begin{array}{l}\text { Patient vitally } \\
\text { dependable on CIED }\end{array}$} & \multirow[b]{2}{*}{ Pacemaker } & \multicolumn{2}{|c|}{ ICD } \\
\hline & & & $\begin{array}{l}\text { Anti-bradycardia } \\
\text { function }\end{array}$ & $\begin{array}{l}\text { Anti-tachycardia } \\
\text { function }\end{array}$ \\
\hline $\begin{array}{l}\text { No electrocutter } \\
\text { usage }\end{array}$ & Yes/no & $\begin{array}{l}\text { No reprogramming } \\
\text { needed }\end{array}$ & $\begin{array}{l}\text { No reprogramming } \\
\text { needed }\end{array}$ & $\begin{array}{l}\text { No reprogramming } \\
\text { needed }\end{array}$ \\
\hline \multirow{2}{*}{$\begin{array}{l}\text { With usage of } \\
\text { electrocutter }\end{array}$} & Yes & Apply magnet & Reprogramming & Apply magnet \\
\hline & No & Magnet available & Apply magnet & Apply magnet \\
\hline
\end{tabular}

Note: For surgical procedures using electrocutters, recommendations relate to the situation when the application of a magnet is available (depending on the surgery location, as well as the patient position) and when the CIED is not within the operating field. In this case, reprogramming of the CIED is required. Also, when there is no appropriate response to the application of magnet, reprogramming is required.

(ECG). If ECG shows the patient's own rhythm or change of the patient's rhythm and pacing, it can be assumed that the patient is not vitally dependent. If there are no medical data, and there is only pacing rhythm on ECG, in urgent situations it can be assumed that the patient is vitally dependent on antibradycardia pacing. Most patients with an ICD are not vitally dependent on anti-bradycardia pacing (because the primary function is anti-tachycardia pacing and defibrillation), although pacing in needed in up to $25 \%$ of patients.

Indications for reprogramming or use of magnet are shown in Table 3.

Absolute indications for CIED testing/reprogramming before the surgery are the following:

1) suspicion of device malfunction/inadequate response to magnet use;

2) use of electrocautery during surgery in patients dependent on anti-bradycardia pacing and surgery is performed in the area of or close to the CIED, or the CIED is not available for magnet application during surgery;

3) use of electrocautery in patients dependent on anti-bradycardia pacing who have an ICD; and

4) use of electrocautery in patients with ICD and surgery is performed in the area of ICD or the ICD is not available for magnet application during surgery.

\section{Intraoperative Care}

In addition to the usual care during surgery, there are a few specific rules for patients with CIED:
- continuous monitoring of heart rhythm;

- during surgery, external defibrillator with the possibility of transcutaneous pacing and with self-adhesive electrodes must be available (because in patients with ICD, detection and treatment function are deactivated, and in all patients with CIED, especially those vitally dependent on anti-bradycardia pacing, complications and asystole occurrence are possible); and

- magnet should be available (see above).

\section{Pacemakers}

If the patient is not dependent on anti-bradycardia pacing, the surgery can be performed without the use of magnet (however, magnet must be available). In patients vitally dependent on anti-bradycardia pacing, magnet application during surgery switches the pacemaker in asynchronous mode of pacing (AOO, VOO, DOO). In patients with pacemakers produced by Biotronik, after the magnet application the pacemaker stimulates 10 heart contractions in asynchronous mode of pacing, after which it goes back into the programmed mode of pacing. The magnet has to be used again afterwards. As already stated, external defibrillator should be available since ventricular arrhythmias can occur in asynchronous mode of pacing (' $\mathrm{R}$ on $\mathrm{T}$ phenomenon'), although extremely rare.

\section{Implantable cardioverter-defibrillators}

For all patients with ICD, we recommend magnet application for turning off the detection and consequently treatment of ventricular arrhythmias. In case of ventricular arrhythmias (VT/VF), one should simply remove the magnet, which turns on the arrhythmia 


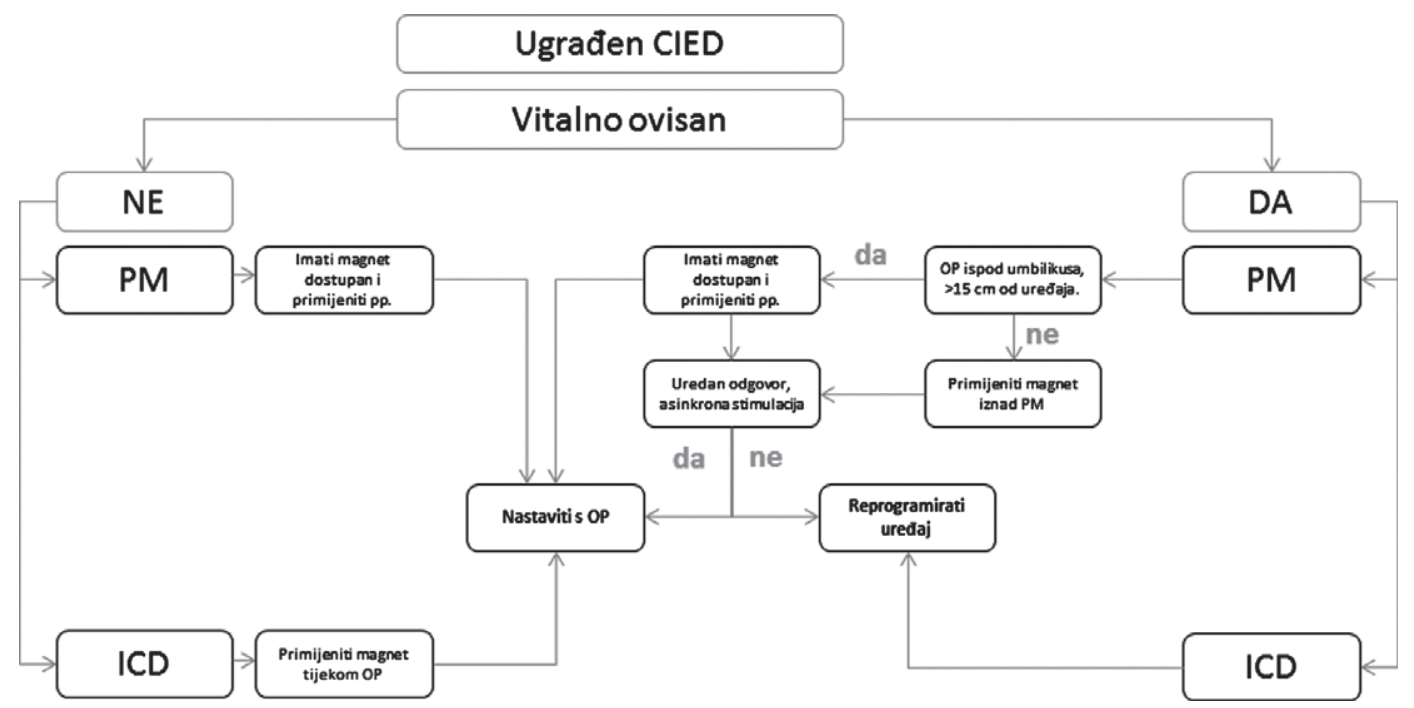

Fig. 3. Algorithm for perioperative management of patients with pacemakers and ICDs.

detection and restores the programmed ICD function. On the other hand, if ICD was reprogrammed (detection switched off) before the surgery, the usage of external defibrillation is an imperative, since the arrhythmia detection is turned off. In patients with ICD who are vitally dependent on anti-bradycardia pacing, it is necessary to reprogram the ICD before the procedure since the magnet does not affect the anti-bradycardia function (only ICD produced by Sorin is an exception; however, in patients with ICD who are vitally dependent on anti-bradycardia pacing the need for reprogramming can be taken as a rule).

\section{Implantable Loop Recorders}

In the case of ILR, one should pay attention to the risk of directly damaging the device. There is no risk for the patient since the device is intended only to monitor the heart rhythm.

\section{Postoperative Care}

After the surgery, it is necessary to monitor patients until the function of CIED is recovered to its pre-surgery function/mode of pacing. In patients for whom the magnet was used, it occurs after removal of the magnet. If the CIED has been reprogrammed preoperatively, monitoring is mandatory until new CIED testing and reprogramming to the previous mode is performed. This is extremely important for patients with ICD in which the detection and treatment of arrhythmias function is turned off before surgery. Besides monitoring, for these patients external defibrillator should be available (in the case of VT/VF occurrence, the ICD will not deliver therapy until the detection mode is turned on).

In patients undergoing thoracotomy during surgery, it is necessary to do chest $\mathrm{x}$-ray to verify the position of the electrodes and also routine postoperative CIED testing/programming ${ }^{6}$. Additional attention should be paid to and a cardiologist consulted, e.g., CIED reprogramming, in patients that develop postoperative shock due to different hemodynamics, as well as limited compensation by increasing heart frequency ${ }^{2,3,7}$.

If the CIED function fails during the surgery, the device or electrodes are directly damaged or the CIED signals some kind of dysfunction by alarm (characteristic for ICD), the patient should be monitored and the device has to be urgently tested and programmed if needed.

\section{Conclusion}

In most patients, most surgical procedures can be done without reprogramming CIED with a simple use of magnet. The basis is to understand the function and response to magnet application for certain CIEDs. It is extremely important to identify patients in whom 
reprogramming is required, and these are primarily patients who are dependent on anti-bradycardia pacing in whom the CIED is not available for magnet application and patients with ICDs who are also dependent on anti-bradycardia pacing.

Magnet application, apart from being simple and for most patients safe, is also a preferred way of perioperative care, which means avoiding repeated, incorrect or incomplete reprogramming.

\section{References}

1. Raatikainen MJ, Arnar DO, Zeppenfeld K, Merino JL, Kuck $\mathrm{KH}$, Hindricks G. Current trends in the use of cardiac implantable electronic devices and interventional electrophysiological procedures in the European Society of Cardiology member countries: 2015 report from the European Heart Rhythm Association. Europace. 2015; Suppl 4: iv1-72. doi: 10.1093/europace/euv265

2. Sticherling C, Menafoglio A, Burri H, et al. Recommendations for the perioperative management of patients with cardiac im- plantable electronic devices. Cardiovasc Med. 2016;19:13-8. https://doi.org/10.4414/cvm.2016.00378

3. Healey JS, Merchant R, Simpson C, et al. Canadian Cardiovascular Society/Canadian Anesthesiologists Society/Canadian Heart Rhythm Society joint position statement on the perioperative management of patients with implanted pacemakers, defibrillators, and neurostimulating devices. Can J Cardiol. 2012;28:141-51. doi: 10.1016/j.cjca.2011.08.121.

4. Pinski SL, Trohman RG. Interference in implanted cardiac devices, part II. Pacing Clin Electrophysiol. 2002;25:1496-509. https://doi.org/10.1046/j.1460-9592.2002.01496.x

5. Jacob S, Panaich SS, Maheshwari R, Haddad JW, Padanilam BJ, John SK. Clinical applications of magnets on cardiac rhythm management devices. Europace. 2011;13:1222-30. doi: 10.1093/europace/eur137

6. Sponga S, Mascioli G, Voisine P, Vitali E. A case of inefficient defibrillation during thoracotomy. J Card Surg. 2011;26:338-9. doi: 10.1111/j.1540-8191.2010.01187.x

7. Stone ME, Apinis A. Current perioperative management of the patient with a cardiac rhythm management devices. Semin Cardiothorac Vasc Anesth. 2009;13:31-43. doi: $10.1177 / 1089253209332211$

Sažetak

\title{
PREPORUKE ZA PERIOPERACIJSKI POSTUPAK KOD BOLESNIKA KOJI IMAJU UGRAĐENE KARDIOVASKULARNE IMPLANTABILNE ELEKTRONIČKE UREĐAJE
}

\author{
N. Pavlovic, Š. Manola, H. Vražić, M. Vučic, S. Brusich, V. Radeljic, I. Zeljković, R. Matasić, A. Anić, I. Benko, \\ Ž. Gavranović i M. Zlatić Glogoški; Radna skupina za aritmije i elektrostimulaciju Hrvatskoga kardiološkog društva
}

U Republici Hrvatskoj na godinu se implantira oko 4000 kardiovaskularnih implantabilnih uređaja i taj broj je u stalnom porastu. Anestezija i kirurški zahvati kod bolesnika s ugrađenim implantabilnim uređajima nose određene rizike. Ove smjernice su nastale zato što se većina zahvata izvodi u ustanovama bez mogućnosti testiranja i reprogramiranja navedenih uređaja ili u vrijeme kada to nije dostupno. Cilj je standardizirati perioperacijsku skrb ovih bolesnika te učiniti kirurške zahvate dostupnima i sigurnima za veliku većinu ovih kirurških bolesnika u svim ustanovama u Hrvatskoj.

Ključne riječi: Hrvatska; anestezija, opća; srčana resinkronizacijska terapija, uređaji; smjernice; perioperationa skrb 